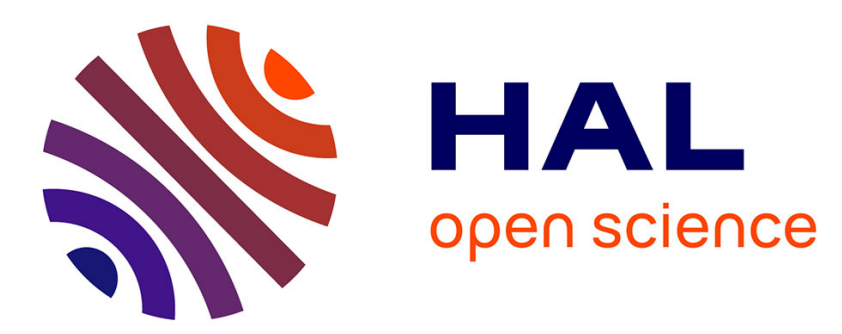

\title{
Surface effect of nano-sized cerium-zirconium oxides for the catalytic conversion of methanol and $\mathrm{CO} 2$ into dimethyl carbonate
}

\author{
Cécile Daniel, Yves Schuurman, David Farrusseng
}

\section{To cite this version:}

Cécile Daniel, Yves Schuurman, David Farrusseng. Surface effect of nano-sized cerium-zirconium oxides for the catalytic conversion of methanol and CO2 into dimethyl carbonate. Journal of Catalysis, inPress, 10.1016/j.jcat.2020.09.023 . hal-03095380

\author{
HAL Id: hal-03095380 \\ https://hal.science/hal-03095380
}

Submitted on 4 Jan 2021

HAL is a multi-disciplinary open access archive for the deposit and dissemination of scientific research documents, whether they are published or not. The documents may come from teaching and research institutions in France or abroad, or from public or private research centers.
L'archive ouverte pluridisciplinaire HAL, est destinée au dépôt et à la diffusion de documents scientifiques de niveau recherche, publiés ou non, émanant des établissements d'enseignement et de recherche français ou étrangers, des laboratoires publics ou privés. 
1 Surface effect of nano-sized cerium-zirconium oxides for the catalytic

2 conversion of methanol and $\mathrm{CO}_{2}$ into dimethyl carbonate

4 Cécile Daniel*, Yves Schuurman, David Farrusseng

5

6

Université de Lyon, CNRS, IRCELYON, 2 Avenue Albert Einstein, Villeurbanne F-69626, France

\section{Abstract}

The direct synthesis of Dimethyl carbonate (DMC) from methanol and $\mathrm{CO}_{2}$ is a green process which allows $\mathrm{CO}_{2}$ valorization. Among efficient catalysts, ceria, zirconia and cerium-zirconium mixed oxides are often reported as the most active catalysts. In a recent report, we discovered that ceriumzirconium mixed oxides prepared by Flame Spray Pyrolysis (FSP) show greater catalytic activities than those prepared by precipitation, although both exhibit very similar surface area and bulk features. The objective of this study was to find out the origins of the superior catalytic activities obtained by flame spray pyrolysis synthesis method by a deeper analysis of bulk and surface properties. We have opted to focus on mixed ceria-zirconia of equimolar composition $\left(\mathrm{Ce}_{0.5} \mathrm{Zr}_{0.5} \mathrm{O}_{2}\right)$ as it exhibits maximum catalytic activity for both synthesis methods. Combining bulk and surface characterization as well as surface adsorption measurements using probe molecules, we propose that flame spray pyrolysis enables a surface enrichment in cerium oxide still in interaction with zirconium oxide that leads to a high concentration of adsorbed methanol at the surface, which might explain the greater activity of the catalysts prepared using this method. Beyond the application of DMC synthesis, we can anticipate that Flame Spray Pyrolysis synthesis should generate relative high surface area mixed oxides with different catalytic performances with respect to mixed oxides prepared at lower temperature owing their metastable nature.

Keywords: methanol; $\mathrm{CO}_{2}$; cerium; surface structure; flame spray pyrolysis; DMC 
1. Introduction

Among organic carbonates, dimethyl carbonate $(D M C)$ is a promising green chemical because of its low toxicity and rapid biodegradability [1][2]. Its versatile chemical properties account for its extensive use as an agent in carbonylation and methylation reactions, replacing $\mathrm{DMSO}, \mathrm{COCl}_{2}$ and $\mathrm{CH}_{3} \mathrm{X}$ [3][4]. It is also widely used as a precursor for the production of polycarbonates and polyurethanes. DMC was historically synthesized by the harmful methanolysis of phosgene. Current industrial processes include hazardous, corrosive oxidative carbonylation in the gas or liquid phase [5]. Other possible routes are the transesterification of propylene carbonate and the methanolysis of urea [6][7].

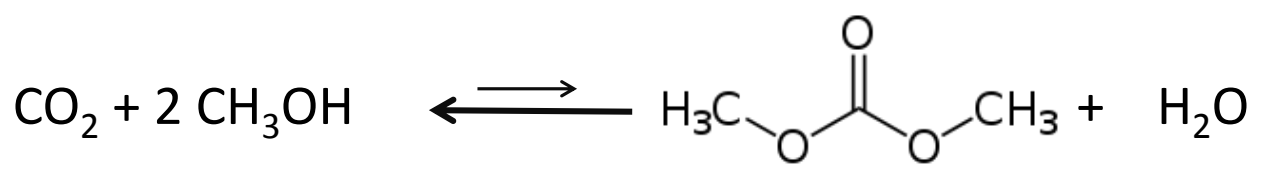

Reaction 1

The direct synthesis of DMC from methanol and $\mathrm{CO}_{2}$ (reaction 1 ) appears particularly attractive: it is a greener alternative to the other routes that simultaneously allows $\mathrm{CO}_{2}$ valorization [7]. However, the methanol conversion in reaction $1, \mathrm{X}_{\mathrm{MeOH}}$, is strongly limited by the thermodynamic equilibrium. DMC yield, assuming $100 \%$ selectivity, can hardly exceed $2 \%$ even under favorable pressure and temperature conditions [8].

Studies demonstrate that a direct synthesis process can technically enable a high DMC yield when an efficient dehydration process is applied [9]. For example, in-situ reactive dehydration of reaction system using 2-cyanopyridine as a dehydration agent led to remarkable enhancement of methanol conversion and DMC yield [10]. Among non-reactive dehydration system, the application of catalytic membrane reactors or ex-situ dehydration system [11][12] allowing continuous water withdrawal during reaction has also been proposed. A successful proof of concept [13] was reported combining both a continuous gas-phase reactor fed with a dehydrating agent.

A wide variety of catalysts have already been tested for the direct synthesis of DMC [14][15], including organic metal-alkoxy compounds, metal oxides, metal-supported catalysts and ionic liquids. Due to their relatively high activity, the majority of metal oxide studies deals with ceria, zirconia and 
cerium-zirconium mixed oxides [16] [17][18][19] [20] [21] [22] [23] or "doped" versions thereof [24][25] [26][27]. Current state of the art of DMC synthesis over ceria-based catalysts is detailed elsewhere [28]. Among rare earth oxide elements, $\mathrm{Y}_{2} \mathrm{O}_{3}$ was also reported [29] to catalyze DMC synthesis at $353 \mathrm{~K}$, one of the lower temperature reported for this reaction.

It is acknowledged that "well-balanced acidic and basic" properties play a key role in DMC synthesis for methanol activation [21] [24][16]. Thermal desorption (TPD) of $\mathrm{NH}_{3}$ and $\mathrm{CO}_{2}$ probe molecules is often used to characterize acid and basic sites, respectively. In [30] Kumar et al. synthesized porous, spherical cerium-zirconium oxide catalysts $\left(\mathrm{Ce}_{x} \mathrm{Zr}_{1-x} \mathrm{O}_{2}\right)$ with different molar ratios. Within this serie, the $\mathrm{Ce}_{0.5} \mathrm{Zr}_{0.5} \mathrm{O}_{2}$ catalyst was found to present the highest concentration of basic and acid sites and the highest DMC yield. Fu et al. [31] established a relationship between the initial rate of DMC synthesis and the surface acidity/alkalinity of $1 \mathrm{D} \mathrm{CeO}_{2}$ nanowires as measured by TPD. Giram et al. [32] investigated the synthesis of diethyl carbonate over metal-incorporated ceria catalysts and reported an optimal dependence of the catalytic activity on the acidity/basicity ratio as measured by $\mathrm{NH}_{3}$-TPD and $\mathrm{CO}_{2}$-TPD. Tomishige et al. [33] carried out propylene carbonate and ethylene carbonate synthesis over $\mathrm{CeO}_{2}-\mathrm{ZrO}_{2}$ solid solutions. They reported that the formation rate per acidic and/or basic sites significantly increased on the catalysts calcined at higher temperature despite lower surface area, and suggested that weak acidic/ basic site may promote activity.

On the other hand, the concentration of oxygen vacancies as measured by the oxygen storage capacity (OSC) of mixed oxides has been reported to be a feature that can determine the degree of acidity or basicity. It has been extensively reported that intermediate ceria-zirconia compositions (i.e., $0.2<x<0.8$ ) are more active than are pure oxides for DMC synthesis, regardless of the synthesis method (for example, sol-gel [21][23], coprecipitation [34] or templating [20]). It has been clearly reported that the highest OSC of cerium-zirconium mixed oxides is also achieved for intermediate compositions $(0.4<x<0.7)$ [35][36]. Although some authors have identified a matching pattern between the OSC and the DMC yield as a function of Ce-Zr composition, a direct link between oxygen vacancies (i.e., the oxidation state of cerium) and the DMC yield has not been clearly established. Wang et al. [37] synthesized $\mathrm{CeO}_{2-x}$ quantum dots, and measured a yield five times higher than for commercial ceria nanoparticles. Marciniak [38] loaded $\mathrm{CeO}_{2}$ with a small amount of $\mathrm{Cu}$, reporting 
that the highest catalytic activity and selectivity toward DMC were obtained with $0.02 \mathrm{wt} . \% \mathrm{Cu}$, mostly due to basic sites associated with the presence of oxygen vacancies. In [39] Liu focused on doping the ceria lattice with $\mathrm{Zr}$ atoms, producing a fluorite-like solid solution and promoting the formation of oxygen vacancy sites. $\mathrm{Zr}_{0.1} \mathrm{Ce}$ nanorods, which exhibited the highest $\mathrm{DMC}$ synthesis activity, also presented the highest concentration of oxygen vacancies. FTIR results demonstrated that $\mathrm{CO}_{2}$ can adsorb on the oxygen vacancy to form bidentate carbonate, which serves as an intermediate in the reaction [33][30]. Katagiri [40] observed a correlation between the number of surface bidentate species and the catalytic activity over $\mathrm{ZrO}_{2}$ nanocrystals [39][39][39][38][38][37][37][36][35][34]. Generally, the density of oxygen vacancies is associated with the occurrence of defects and $\mathrm{Ce}^{3+}$ cations, which, however, have been reported not to be active sites [41]. Indeed, Aresta established that $\mathrm{Ce}^{4+}$ is the active cation species, whereas $\mathrm{Ce}^{3+}$ is inactive [27]. Also, Liu prepared $\mathrm{Ce}_{0.5} \mathrm{Zr}_{0.5} \mathrm{O}_{2}$ by different methods, showing that the direct carboxylation of methanol is mostly correlated with the proportion of $\mathrm{Ce}^{4+}$ in the catalyst surface [22].

In a recent study [42] we set up a reliable protocol to measure catalytic activity over a diverse library of catalysts. The screening we carried out reveals the outstanding activity of ceria-zirconia flamesprayed catalysts. Surprisingly, although coprecipitated and flame-sprayed catalysts apparently show similar surface areas and bulk composition, they perform very differently.

The aim of this work is to investigate the origin of different catalytic activities for two synthesis methods: coprecipitation and flame spray pyrolysis. We have opted to focus on mixed ceria-zirconia of equimolar composition $\left(\mathrm{Ce}_{0.5} \mathrm{Zr}_{0.5} \mathrm{O}_{2}\right)$ as it exhibits maximum catalytic activity for both synthesis methods. Nevertheless, we have investigated a series of ceria-zirconia solids with compositions spanning from pure ceria to pure zirconia in order to facilitate the identification of trends in their properties. Combining bulk and surface characterization as well as surface adsorption measurements using probe molecules, we propose that flame spray pyrolysis enables a surface enrichment in ceria in close interaction with zirconium oxide that leads to a high concentration of adsorbed methanol at the surface, which might explain the greater activity of the catalysts prepared using this method. 


\section{Materials and methods}

\subsection{Synthesis of catalysts}

Two series of ceria-zirconia solids ranging from pure zirconia to pure ceria were prepared: one by flame spray pyrolysis and the other by coprecipitation. The flame spray pyrolysis samples, hereafter denoted FSP, were synthesized by Johnson Matthey following a protocol described in [43] [44]. The general principle can be summarized as follow. Aqueous metal salt solutions were prepared with desired concentration of metals. The solutions were sprayed as a fine mist into a flame (up to $2200^{\circ} \mathrm{C}$ ). High space velocities and heat radiation loss lead to extremely short residence times (milliseconds) with high temperature gradients up to $170{\mathrm{~K} . \mathrm{cm}^{-1}}^{-1}$ along the flame axis [45]. The metal oxide atoms aggregated into nanoparticles, which were then collected on a filter.

Coprecipitated catalysts, denoted $\mathrm{CP}$, were synthesized from the appropriate nitrate salts using $\mathrm{NaOH}$ as the precipitating agent, as described in an earlier publication [42]. The coprecipitated solids were heat-treated in air at $500^{\circ} \mathrm{C}(\mathrm{CP}-500)$ and $850^{\circ} \mathrm{C}(\mathrm{CP}-850)$ for 4 hours. The temperature of $850^{\circ} \mathrm{C}$ was chosen to obtain catalysts with higher crystallinity and a relatively high surface area similar to those of the catalysts prepared by flame spray pyrolysis.

The subscript $\mathrm{x}$ hereafter stands for the molar cerium content in $\mathrm{Ce}_{\mathrm{x}} \mathrm{Zr}_{1-\mathrm{x}} \mathrm{O}_{2}$ solids as determined by elemental analysis. As indicated above, the results presented here focus on the mixed oxides prepared by the two methods and presenting approximately equal cerium and zirconium contents, because they are representative and relevant solids. The notations CZ-CP and CZ-FSP refer to solids of composition $\mathrm{Ce}_{0.45} \mathrm{Zr}_{0.55} \mathrm{O}_{2}$ for coprecipitation and $\mathrm{Ce}_{0.5} \mathrm{Zr}_{0.5} \mathrm{O}_{2}$ for flame spray pyrolysis, respectively.

\subsection{Catalytic activity measurements}

The evaluation of catalyst activities was carried out using a method detailed in [42]. In short, the triphasic catalytic carboxylation of methanol was carried out in a high-pressure Parr Instrument vessel of $50 \mathrm{~mL}$ volume equipped with a pressure indicator and used as a batch reactor. Typically, an adjusted amount of dried catalyst in powder form (ranging from $20 \mathrm{mg}$ to $500 \mathrm{mg}$ ) and $12 \mathrm{~g}$ of methanol with $0.1 \mathrm{wt} . \%$ anhydrous toluene as internal standard were introduced into the vessel. The amount of catalyst was adjusted so that the methanol conversion was always lower than $0.6 \%$ after a 
4-hour reaction time. Then an $18-\mathrm{mL}$ volume of liquid $\mathrm{CO}_{2}$ kept at $4^{\circ} \mathrm{C}$ and 50 bar was fed into the autoclave by an Isco 250D syringe pump. The vessel was heated under magnetic stirring in an oil bath at $140^{\circ} \mathrm{C}$ for 4 hours. Finally, the vessel was cooled down in an ice bath.

Only DMC was detected as product (Shimadzu GCMS-QP2010 equipped with a ZB-WAX column). The amount of DMC produced was quantified by a gas chromatograph (6850 GC Agilent) equipped with a DB-WAXetr capillary column $(30 \mathrm{~m})$ and a flame ionization detector. Catalyst activity is expressed as follows:

$$
\text { Activity }=\frac{n_{D M C}(m o l)}{m_{\text {catalyst }}(g) * \text { time }(s)}
$$

\subsection{Characterization of catalysts}

Elemental analysis of the catalysts was carried out by inductively coupled plasma-optical emission spectrometry (ICP-OES; ACTIVA instrument from HORIBA Jobin Yvon) equipped with a CCD detector for the determination of metal loadings. Measurements were duplicated and the average was calculated. The experimental error is estimated to be $+/-3 \%$.

Catalyst morphology was analyzed by TEM (JEOL 2010 Lab 6) under 200 kV acceleration.

Crystalline phases were characterized by X-ray diffraction and Raman spectroscopy. Data were collected for $2 \theta$ between $4^{\circ}$ and $80^{\circ}$ with a step of $0.02^{\circ}$ using a Bruker D8 A25 Advance diffractometer with $\mathrm{Cu}$ Ka radiation operated at $50 \mathrm{KV}$ and $35 \mathrm{~mA}$. Crystallite sizes were estimated by the Scherrer equation over several diffractogram peaks. Raman spectra were recorded with a Lab RAM HR (Horiba) equipped with an Ar laser (514.4 nm) and a CCD detector.

The surface area structure was measured by nitrogen adsorption at $77 \mathrm{~K}$ using the Brunauer-EmmettTeller (BET) method on a Belsorp MAX instrument (Bel Japan). Prior to measurements, the samples were desorbed at $300^{\circ} \mathrm{C}$ for 3 hours using a Belprep vacuum instrument.

XPS measurements were performed using a Kratos Axis Ultra DLD spectrometer. The base pressure in the analysis chamber was lower than $5 \times 10^{-8} \mathrm{~Pa}$. XPS spectra of O 1s, C 1s, Zr 3d, Zr 3p, Ce $4 d$ and Ce $3 \mathrm{~d}$ levels were measured at $90^{\circ}$ (the normal angle with respect to the plane of the surface) using a monochromated Al Ka X-ray source with a pass energy of $20 \mathrm{eV}$ and a spot size aperture of $300 \mu \mathrm{m}$. 
Binding energies were corrected relative to the $\mathrm{C} 1 \mathrm{~s}$ signal at $284.6 \mathrm{eV}$. The atomic compositions in cerium and zirconium were determined using the Ce3d and Zr3p signals by integrating the areas under the corresponding peaks after subtracting the Shirley background. Same $\mathrm{Ce} / \mathrm{Zr}$ ratio trends were obtained by using Ce4d and Zr3d signals instead (results not shown).

The total acidity and basicity of the oxides were quantified by the temperature-programmed desorption (TPD) of probe molecules (ammonia and $\mathrm{CO}_{2}$, respectively). The TPD of ammonia and $\mathrm{CO}_{2}$ ( $\mathrm{NH}_{3}$-TPD, $\mathrm{CO}_{2}$-TPD) were carried out on a homemade device. Typically, $100 \mathrm{mg}$ of powdered sample were dried and desorbed for 1 hour at $300^{\circ} \mathrm{C}$ under helium flow. Adsorption of $\mathrm{CO}_{2}$ was carried out at $30^{\circ} \mathrm{C}$ under a flow of 20 vol.\% $\mathrm{CO}_{2}$ in $\mathrm{He}$, whereas adsorption of $\mathrm{NH}_{3}$ was carried out at $100^{\circ} \mathrm{C}$ in a 5 vol.\% $\mathrm{NH}_{3}$ stream. Then the sample was purged under He flow for one hour to remove weakly adsorbed probe molecules. Programmed desorption was carried out under He with a heating rate of $10^{\circ} \mathrm{C} \cdot \mathrm{min}^{-1}$ and a flow rate of $25 \mathrm{~mL} \cdot \mathrm{min}^{-1}$. Desorption of probe molecules was measured with a mass spectrometer (Transpector II Inficon) during the heating step. The total number of basic sites was calculated by integrating the flow of $\mathrm{CO}_{2}$ desorbed by TPD between 50 and $700^{\circ} \mathrm{C}$, while the total number of acid sites was calculated by integrating the flow of $\mathrm{NH}_{3}$ desorbed between 80 and $400^{\circ} \mathrm{C}$.

The nature of surface hydroxyl species and the coordination number of oxides were investigated by diffuse reflectance infrared Fourier transform spectroscopy (DRIFTS), as the nature of the hydroxyl groups can vary considerably depending on the exposed (111) or (100) surface or on the degree of reduction [46]. Catalyst spectra were recorded on a Magna 550 Nicolet spectrometer with a resolution of $4 \mathrm{~cm}^{-1}$ and 32 scans.

The surface was characterized upon methanol adsorption using a DRIFTS cell (Harrick Scientific). Methanol is a relevant probe molecule since it is a reactant in DMC synthesis. Prior to adsorption, the catalysts were dried in situ under $\mathrm{Ar}$ flow at $250^{\circ} \mathrm{C}$. 


\section{Results}

\subsection{Structural characterization}

187

Fig. 1 (left) shows a transmission electron micrograph of flame-sprayed CZ-FSP featuring free, highly crystalline octahedral particles between 5 and $10 \mathrm{~nm}$ in size. No sintering or agglomeration is visible. The morphology dominated by $\{111\}$-enclosed octahedral particles was also found in other flamesprayed ceria-zirconia samples described in [44][47] . On the other hand, coprecipitated CZ-CP-500

(Fig. 1, centre) exhibits rough agglomerated particles of irregular shape that are much less crystalline but of similar size $(5-10 \mathrm{~nm})$ compared to the FSP sample. The level of crystallinity of the coprecipitated $\mathrm{CP}-500$ set of samples increases with thermal treatment at $850^{\circ} \mathrm{C}$, as indicated by larger fringe domains and the clearly visible sintering of particles. (CZ-CP-850, Fig. 1, right). Nevertheless, the surface of the coprecipitated solid even treated at $850^{\circ} \mathrm{C} C Z-\mathrm{CP}-850$, remains less

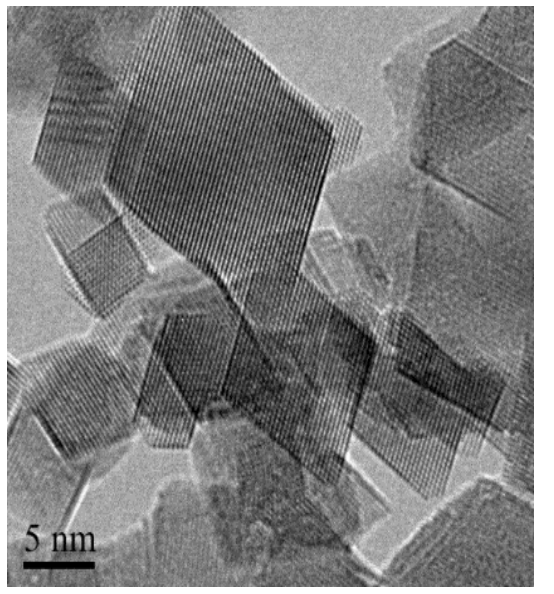

organized t6]1r-Fo\$ RZ-FSP solid.

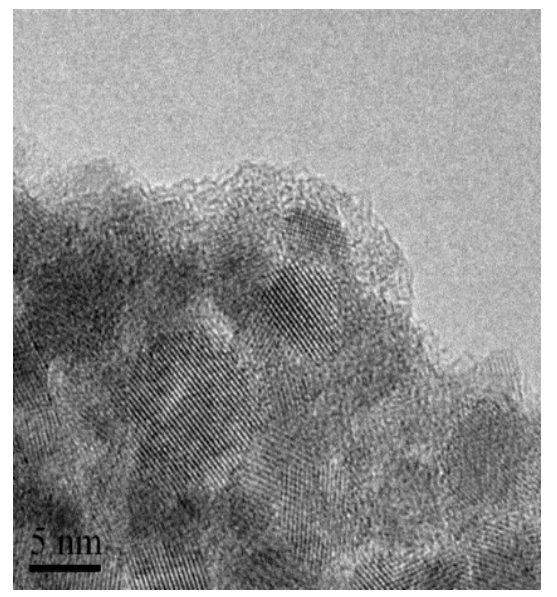

CZ-CP-500

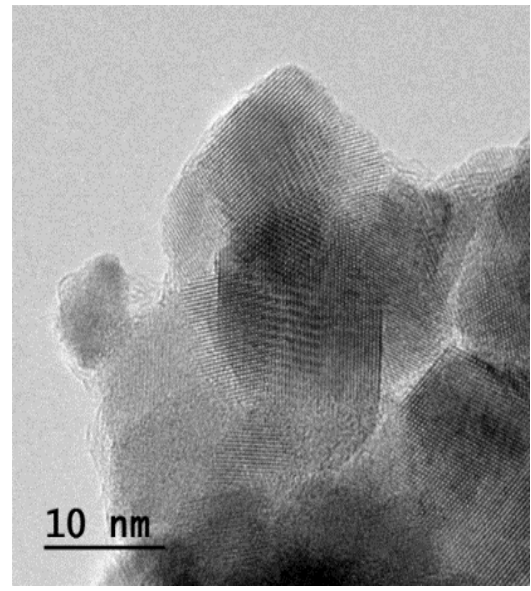

CZ-CP-850

Fig. 1: TEM images of CZ-FSP ( $x=0.5$, left), CZ-CP-500 ( $x=0.45$, center) and CZ-CP-850 $(x=0.45$, right $)$ 
The specific surface areas of the FSP and coprecipitated ceria-zirconia catalysts are reported in Figure

203

204

2. Except when the solid compositions approach those of pure ceria or zirconia, the surface area of mixed oxides is relatively insensitive to composition, as can be seen by the plateau at compositions $0.3<x<0.8$. While FSP oxides exhibit surface areas in the range of $90(+/-10) \mathrm{m}^{2} \cdot \mathrm{g}^{-1}$, the CP-500 samples have slightly higher surface areas in the range of $120(+/-10) \mathrm{m}^{2} \cdot \mathrm{g}^{-1}$, in good agreement with earlier reports for these two synthesis methods [44][47]. The thermal treatment at $850^{\circ} \mathrm{C}$ applied on coprecipitated oxides yields lower surface areas in line with the sintering observed on the TEM images. As reported elsewhere in the literature [48] [49], an addition of zirconia to ceria limits sintering during thermal treatments. Importantly, we can see a plateau at compositions $0.3<x<0.8$ for CP-850, with specific surface areas in the range of $40(+/-3) \mathrm{m}^{2} . \mathrm{g}^{-1}$. For the equimolar ceriazirconia samples (denoted CZ), the surface areas are 99, 119 and $42 \mathrm{~m}^{2} \cdot \mathrm{g}^{-1}$, for CZ-FSP, CZ-CP-500 and CZ-CP-850, respectively.

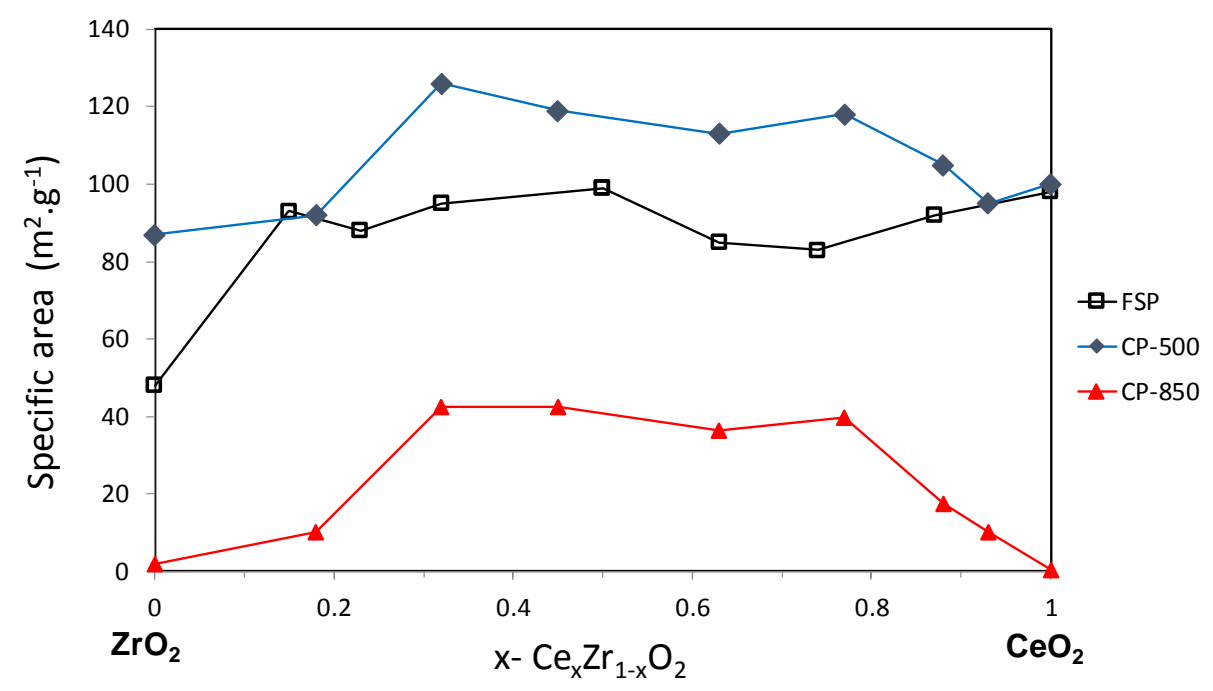

Fig. 2: Specific surface area of flame spray pyrolysis (FSP) $(\square)$ and coprecipitated oxide catalysts fired at $500^{\circ} \mathrm{C}(\mathrm{CP}-500)\left(\right.$ and $850^{\circ} \mathrm{C}(\mathrm{CP}-850)(\boldsymbol{\Delta})$

The mean sizes of the crystallized domains were estimated by applying the Scherrer method to several peaks of the diffraction pattern $(\mathrm{SI})$. The $850^{\circ} \mathrm{C}$ heat treatment conducted on the coprecipitated oxides led to significantly sharpened diffraction peaks. Similarly to surface area, 
crystallite sizes are insensitive to oxide composition for $0.3<\mathrm{x}<0.8$. In this region, the CP-500 and FSP mixed oxides show crystallite sizes ranging between 5 and $10 \mathrm{~nm}$ which is coherent with TEM pictures. The crystallized domain sizes of the CP-850 samples are systematically higher than those of the corresponding CP-500 samples, in agreement with the sintering phenomena observed. Crystalline domain sizes increase when compositions approach pure oxides (either $\mathrm{CeO}_{2}$ or $\mathrm{ZrO}_{2}$ ), especially for CP-850. For ceria-zirconia of equivalent $(x=0.5)$ content ( $C Z$ samples), the mean crystalline domain sizes are 5 (+/-1) for CZ-FSP, CZ-CP-500 and CZ-CP-850, respectively.

The X-ray diffraction patterns of the coprecipitated series heat-treated at $500^{\circ} \mathrm{C}$ or $850^{\circ} \mathrm{C}(\mathrm{CP}-500$, CP-850) exhibit a continuous shift in peak reflection as the $\mathrm{Zr}$ content increases attesting to the synthesis of solid solutions [50] (SI). Only pure zirconia exhibits a different pattern featuring both monoclinic and tetragonal phases. The X-ray patterns of the FSP samples also reflect the mixing of ceria and zirconia over the whole range of compositions $(0.15<x<0.87)$, indicating the existence of a set of solid solutions.

The XRD peak broadening caused by the nano-size of the particles does not allow clear identification of phases, even by Rietveld refinement. We referred to the existing literature to conduct a tentative assignment of crystalline phases by crossing information with the Raman spectra [49] [51] [52] (see $\mathrm{SI}$ ). By crossing the Raman spectra and the X-ray diffraction patterns, we can confirm the formation of ceria-zirconia solid solutions as in [53]. We have noticed that, irrespective of the synthesis method, cerium-zirconium oxides crystallize in the same phase for a given composition $\mathrm{x}$. For example, for $\mathrm{CZ}$ oxides $(\mathrm{x}=0.5)$, very similar ceria-zirconia spectra featuring a $\mathrm{t}^{\prime}$ tetragonal phase are observed. 


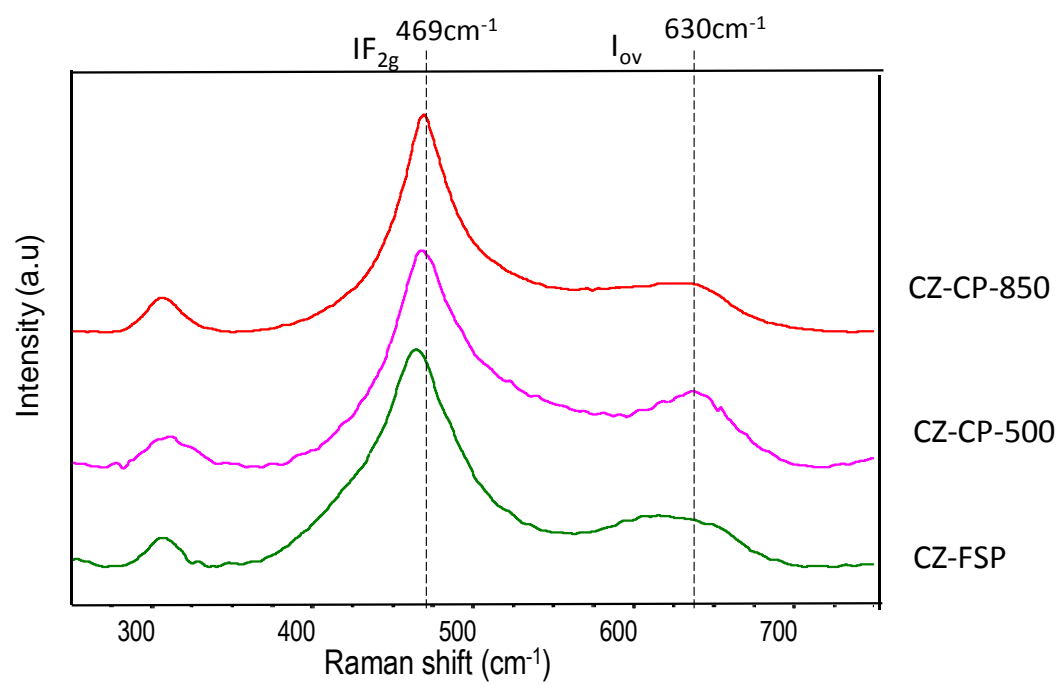

244 Fig. 3: Raman spectra of CZ-CP-500 (violet), CZ-CP-850 (red) and CZ-FSP (green)

246 The band at $630 \mathrm{~cm}^{-1}$ is commonly assigned to oxygen vacancies caused by $\mathrm{Ce}^{3+}$ in the $\mathrm{CeO}_{2}$ lattice

247 [54][55]. The ratio of the intensity of the band at $630 \mathrm{~cm}^{-1}$ (oxygen vacancies / $\mathrm{I}_{\mathrm{ov}}$ ) to that of $\mathrm{IF}_{2 \mathrm{~g}}(464$

$248 \mathrm{~cm}^{-1}$ ) reflects the concentration of defects in the oxide [56] (Table 1). We can see that the ratio of

249 oxygen vacancies is similar for the CP-850 and FSP series for compositions ranging from $\mathrm{x}=0.45$ to

$250 x=1$. In contrast, we can see a significant oxygen vacancy decrease after the heat treatment of CP-500

251 leading to CP-850, for the composition $\mathrm{x}=0.45$.

252

253 Table 1 : Defect concentration in oxides estimated by Raman spectroscopy

\begin{tabular}{|c|c|c|}
\hline $\begin{array}{c}\mathrm{CeO}_{2} \\
\text { content (x) }\end{array}$ & $\begin{array}{l}\text { Synthesis } \\
\text { method }\end{array}$ & $\mathrm{I}_{\mathrm{ov}} / \mathrm{IF}_{2 \mathrm{~g}}$ \\
\hline 1 & FSP & 0.02 \\
\hline 1 & CP-850 & 0.01 \\
\hline 0.74 & FSP & 0.10 \\
\hline 0.77 & CP-850 & 0.09 \\
\hline 0.63 & FSP & 0.10 \\
\hline
\end{tabular}




\begin{tabular}{|l|l|l|}
\hline 0.63 & CP-850 & 0.11 \\
\hline 0.5 & FSP & 0.23 \\
\hline 0.45 & CP-850 & 0.22 \\
\hline 0.45 & CP-500 & 0.37 \\
\hline
\end{tabular}

254

255

256

257

258

259

260

261

262

263

264

265

266

267

268

269

270

271

272

273

274

275

276

\subsection{Surface characterization}

Surface compositions in cerium and zirconium were determined by peak integration of $\mathrm{Ce}_{3 \mathrm{~d}}$ and $\mathrm{Zr}_{3 p}$ for the each mixed-oxide FSP series and four CP solids (SI). We found that for all solids, the estimated binding energies (181.85+/-0.05 for $\mathrm{Zr}_{3 \mathrm{~d}}$ and $882.2+/-0.2$ for $\left.\mathrm{Ce}_{3 \mathrm{~d}}\right)$ are similar to values reported in the literature [57][58]. We remind here that XPS results probe a depth ranging between $3 \mathrm{~nm}$ and $10 \mathrm{~nm}$ depending on samples and that the first layer would impact for about $10 \%$ of the signal intensity. Hence XPS is sensitive to metal segregation at the surface even if a few atomic layers are probed. Interestingly, two characteristic signals of $\mathrm{Ce}^{3+}$ at $884 \mathrm{eV}\left(\mathrm{v}^{\prime}\right)$ and the shoulder $903 \mathrm{eV}\left(\mathrm{u}^{\prime}\right)$ are more pronounced in the case of $\mathrm{CP}-500$ which is in good line with defect concentrations estimated by Raman results (Table 1).

We have plotted a parity diagram of surface molar composition estimated by XPS as a function of the bulk composition analyzed by ICP-OES (Fig. 4). Importantly, we can observe that the surface composition is the same as the bulk composition for the three CP-850 oxides analyzed here. In addition, we can note the very good matching of bulk and surface compositions for the coprecipitated oxides with a molecular cerium composition of $x=0.45$. As expected, the bulk compositions of CZ-CP 500 and CZ-CP 850 are identical, since the CZ-CP 850 is obtained by the heat treatment of CZ-CP 500.

By contrast, the FSP oxide series systematically shows a discrepancy between the compositions analyzed by XPS and those analyzed by ICP-OES. Indeed, the XPS results indicate an enrichment of cerium at the surface. The exact location and depth of this cerium surface enrichment can hardly be 
277 estimated, however. For the CZ-FSP sample of bulk composition $\mathrm{Ce}_{0.5} \mathrm{Zr}_{0.5} \mathrm{O}_{2}$, the surface composition 278 estimated by XPS would be $\mathrm{Ce}_{0.57} \mathrm{Zr}_{0.43} \mathrm{O}_{2}$. To our knowledge, surface composition analyses of cerium279 zirconium mixed oxides synthesized by flame spray pyrolysis have not been reported elsewhere.

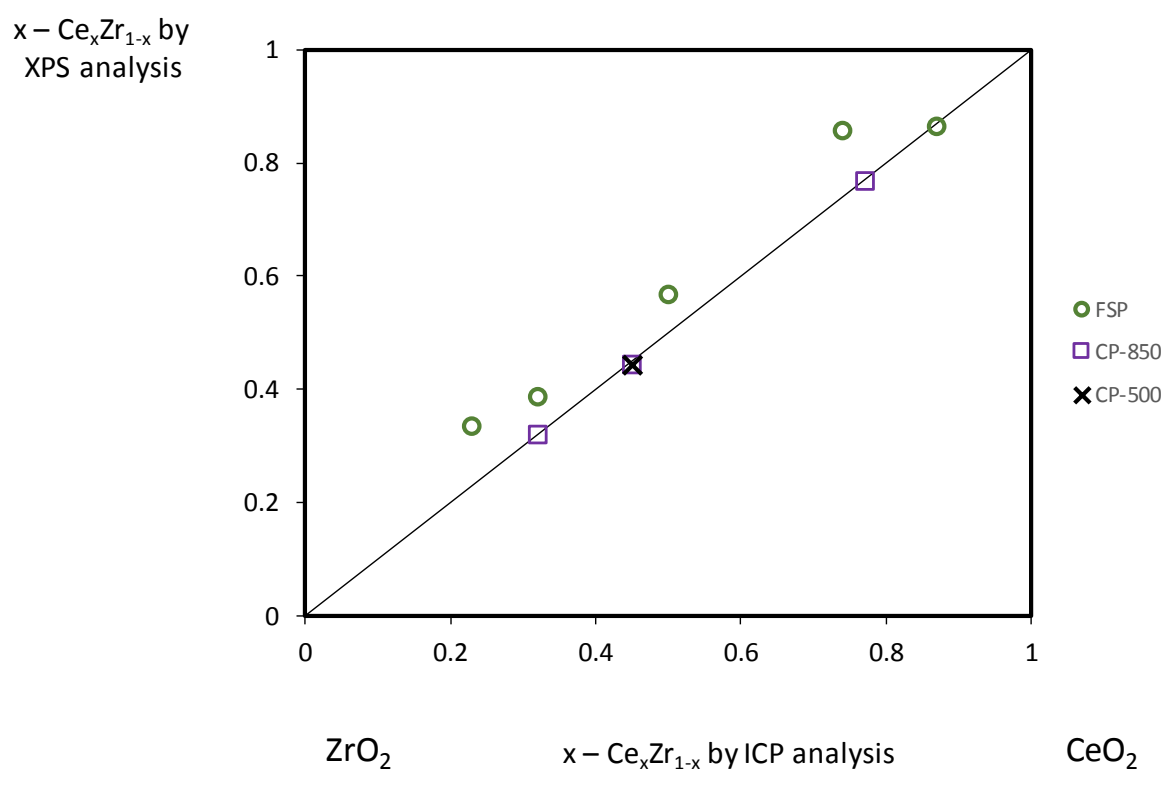

Fig. 4: Parity diagram of molar composition $x$ measured by XPS versus molar composition $x$ measured by ICP-OES for (o) FSP, ( $\square$ ) CP-850 and (x) CP-500 solids The structure of the hydroxyl groups on ceria and zirconia has been characterized by FTIR as a 288 function of temperature. It is recognized that the wavelength of the $\mathrm{OH}$ species associated with the temperature originates from the nature of the hydroxyls and their local reorganization [67] [60][61]. 


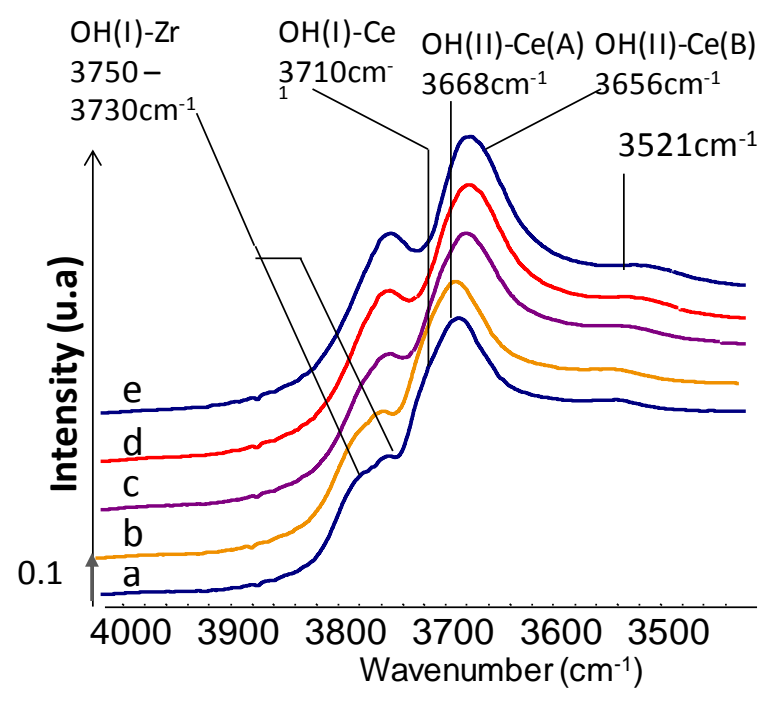

(A) CZ-CP-500
291

292

293

294

295

296

297

298

299

300

301

302

303

304

305

306

307

308

309

Fig. 5: DRIFTS in the $\mathrm{OH}$ region of $\mathrm{CZ}$ oxides with $\mathrm{x} \approx 0.5$ as a function of temperature at (a) $100^{\circ} \mathrm{C}$; (b) $200^{\circ} \mathrm{C}$; (c) $300^{\circ} \mathrm{C}$; (d) $400^{\circ} \mathrm{C}$; and (e) $500^{\circ} \mathrm{C}$; sample CZ-CP-500 (left), sample CZ-FSP (right).

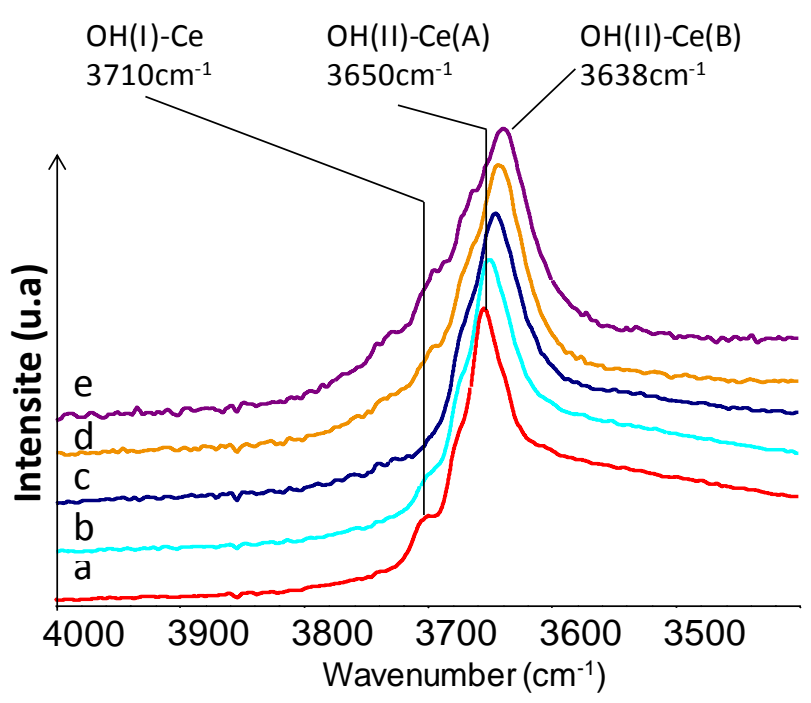

(B) CZ-FSP

The CZ CP-500 solid exhibits both hydroxyls $\mathrm{OH}(\mathrm{I})-\mathrm{Zr}$ at $3750 \mathrm{~cm}^{-1}$ and $\mathrm{CeOH}(\mathrm{I})-\mathrm{Ce}$ at $3710 \mathrm{~cm}^{-1}$ at $100^{\circ} \mathrm{C}$ (Fig. 5A). Upon thermal treatment, the $\mathrm{OH}(\mathrm{I})$ - $\mathrm{Zr}$ signal remains, while the $\mathrm{OH}(\mathrm{II})-\mathrm{Ce}(\mathrm{A})$ hydroxyl signal at $3668 \mathrm{~cm}^{-1}$ shifts to $\mathrm{OH}(\mathrm{II})-\mathrm{Ce}(\mathrm{B})$ at $3656 \mathrm{~cm}^{-1}$, a phenomenon usually associated with the creation of oxygen vacancies next to cerium.

We can note that the DRIFT spectra of the CZ-FSP solid are significantly different from those of CZCP-500 despite similar bulk composition (Fig 5B). Interestingly, the $\mathrm{OH}(\mathrm{I})-\mathrm{Zr}$ hydroxyl signal is not visible. The band corresponding to $\mathrm{OH}(\mathrm{I})-\mathrm{Ce}$ is clearly identified at $3710 \mathrm{~cm}^{-1}$ but vanishes at temperatures higher than $300^{\circ} \mathrm{C}$, while the $\mathrm{OH}(\mathrm{II})$-Ce signals shift progressively from (A) to (B). In summary, DRIFTS also reveals the dominance of ceria hydroxyls at the surface of the FSP oxides, whereas both ceria and zirconia hydroxides are present in the CP oxides.

\subsection{Surface reactivity characterization by probe molecules}

Inspired by the clear differences observed in the $\mathrm{OH}$ region through the use of DRIFTS, we have further investigated the characteristics of the surface by using methanol as a probe molecule, as this 
process can reveal information on the surface composition and heterogeneity of cerium-zirconium oxides [62]. It is important to stress that methanol is a reactant in DMC synthesis and that information on how methanol compensates for the coordinative unsaturation of surface cations is relevant for the kinetics. Methanol dissociation occurs on a Lewis acid/base pair $\left(\mathrm{Zr}^{4+}\right.$ or $\mathrm{Ce}^{4+}$, and $\mathrm{O}^{2-}$ ), yielding different methoxide species that are associated with specific wavelengths [63][64] (see SI). Though the DRIFTS method does not allow the quantitative measurement of surface species, the mean apparent absorption coefficients of $\mathrm{CH}_{3} \mathrm{O}-\mathrm{Ce}(\mathrm{I})$ and $\mathrm{CH}_{3} \mathrm{O}-\mathrm{Zr}(\mathrm{I})$ were nevertheless reported to be equal at $\varepsilon=6.9 \mathrm{~mol}^{-1}$, a situation that permits semi-quantitative analysis [65].

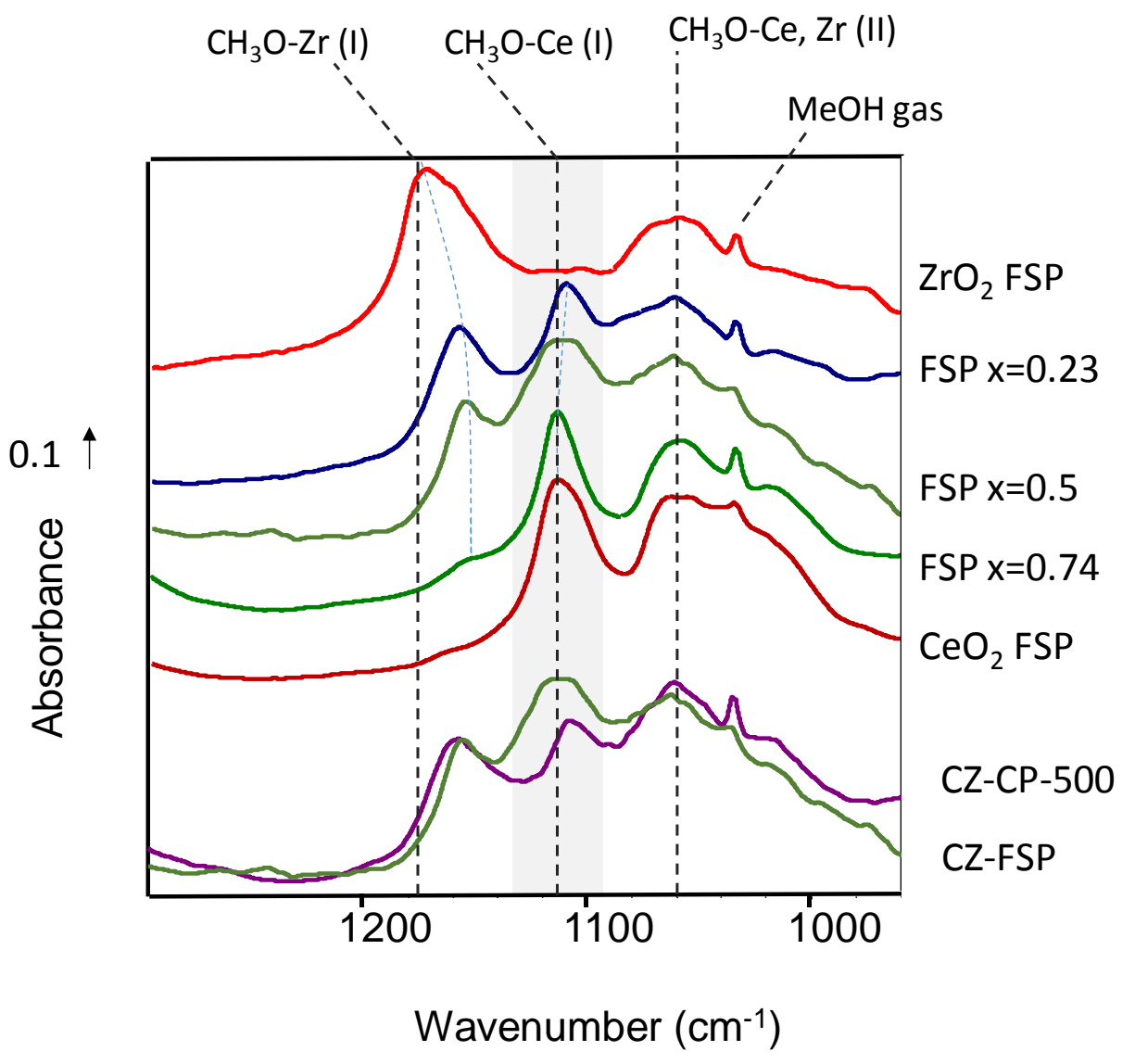

Fig. 6: DRIFTS results under 5 vol. $\% \mathrm{CH}_{3} \mathrm{OH}$ in $\mathrm{Ar}$ flow at $100^{\circ} \mathrm{C}$

DRIFT spectra under methanol adsorption equilibrium for the FSP series (top), along with a 322 comparison with CZ-FSP and CZ-CP-500 (bottom), are plotted in Fig. 6 . A small peak near $1050 \mathrm{~cm}^{-1}$ is 323 attributed to the contribution of gaseous methanol present in the cell. On the spectrum of pure ceria $(x=1)$, the vibration of $\mathrm{CH}_{3} \mathrm{O}-\mathrm{Ce}(\mathrm{I})$ methoxide at $1115 \mathrm{~cm}^{-1}$ is dominant, but it vanishes as the 
concentration of cerium decreases. Inversely, the $\mathrm{CH}_{3} \mathrm{O}-\mathrm{Zr}(\mathrm{I})$ methoxide band at $1171 \mathrm{~cm}^{-1}$, which is intense for the pure zirconium oxide $(x=0)$, vanishes as the cerium content increases. In accordance with earlier publications, a large band at $1060-1080 \mathrm{~cm}^{-1}$ can be assigned to $\mathrm{CH}_{3} \mathrm{O}-\mathrm{Zr}(\mathrm{II})$ and $\mathrm{CH}_{3} \mathrm{O}$ $\mathrm{Ce}(\mathrm{II})$ methoxides [63][64]. For the FSP mixed oxides $(x=0.23,0.5,0.74)$, the four methoxide species described here coexist.

The spectra corresponding to the CZ-FSP and CZ-CP-500 samples of similar composition are compared at the bottom of Fig 6 . The two spectra look relatively similar and feature the presence of the four methoxide species. Yet the band assigned to $\mathrm{CH}_{3} \mathrm{O}-\mathrm{Ce}(\mathrm{I})$ is more intense for FSP and for the CP-500 mixed oxides, unlike the $\mathrm{CH}_{3} \mathrm{O}-\mathrm{Zr}(\mathrm{I})$ bands, which are of similar intensity. This reveals a higher concentration of unsaturated $\mathrm{Ce}^{4+}$ cations on the FSP with respect to the CP-500 oxide.

The surface concentrations of acid and basic sites were quantified by $\mathrm{NH}_{3}$ and $\mathrm{CO}_{2}$ temperatureprogrammed desorption for the whole FSP series and selected CP-850 samples (see SI). TPD results do not reveal significant differences between CZ-FSP and CZ-CP-850 in terms of acid site concentrations $\left(0.15\right.$ versus $\left.0.10 \mu \mathrm{mol} . \mathrm{m}^{-2}\right)$ or basic site concentrations $\left(1.10\right.$ versus $\left.1.19 \mu \mathrm{mol} . \mathrm{m}^{-2}\right)$. In addition, the concentration of basic sites does not vary significantly over the entire range of compositions for the FSP series, in contrast to catalytic activity, which is composition-sensitive as shown below (see SI). Also, the catalytic activity trend cannot be linked to the concentration of acid sites, which does not vary between $x=0.5$ and $x=1.0$ (see $\mathrm{SI}$ ).

\subsection{Catalytic activity in DMC synthesis}

The catalytic activity per mass unit of the three series of ceria-zirconia solids (CP-500, CP-850 and FSP) is reported as a function of cerium composition (Fig. 7). Mixed oxides prepared by FSP are much more active catalysts compared to the coprecipitated oxides at iso-composition. The FSP series exhibits, on average, a five-fold increase in activity compared to CP-800. Irrespective of the synthesis methods, all mixed oxides are more active than pure ceria and zirconia, attesting to a synergistic effect of ceria and zirconia mixing, which is well in line with previous reports [16][23][21]. For each 
352

353

354

355

356

357

358

359

360

361

362

363

364

365

366

367

368

369

370

371

set of catalysts, the activity versus composition curve resembles a volcano plot. The highest activities are obtained for molar compositions $\mathrm{x}$ ranging between 0.4 and 0.8 . For mixed oxides with equal CeZr content $(x=0.5)$, CZ-FSP activity is $6.0 \mu \mathrm{mol} . \mathrm{g}^{-1} \cdot \mathrm{s}^{-1}$ compared to $1.37 \mu \mathrm{mol} . \mathrm{g}^{-1} \cdot \mathrm{s}^{-1}$ and $0.24 \mu \mathrm{mol} . \mathrm{g}^{-1} \cdot \mathrm{s}^{-}$ ${ }^{1}$ for CZ-CP-850 and CZ-CP-500, respectively. Interestingly, the catalytic activities of pure ceria and pure zirconia do not depend on the synthesis method. In particular, the activity gain of FSP mixed oxides is not observed in the cases of $\mathrm{CeO}_{2}$ or $\mathrm{ZrO}_{2}$. This suggests that the higher catalytic activities of the FSP samples could not arise from the particular particle morphology provided by the flame spray synthesis, otherwise higher catalytic activities for ceria and zirconia would also have been seen. Furthermore, we note that the catalytic activity of mixed oxides is not correlated with their surface area (Fig. 8). Although the CP-500 series shows a higher surface area than FSP, these catalysts perform very poorly per surface unit. For mixed oxides with equal Ce-Zr content $(x=0.5)$, the activity of CZ-FSP is $0.06 \mu \mathrm{mol} . \mathrm{m}^{-2} . \mathrm{s}^{-1}$, versus $0.03 \mu \mathrm{mol} . \mathrm{m}^{-2} . \mathrm{s}^{-1}$ and $0.002 \mu \mathrm{mol} . \mathrm{m}^{-2} . \mathrm{s}^{-1}$ for CZ-CP-850 and CZCP-500, respectively.

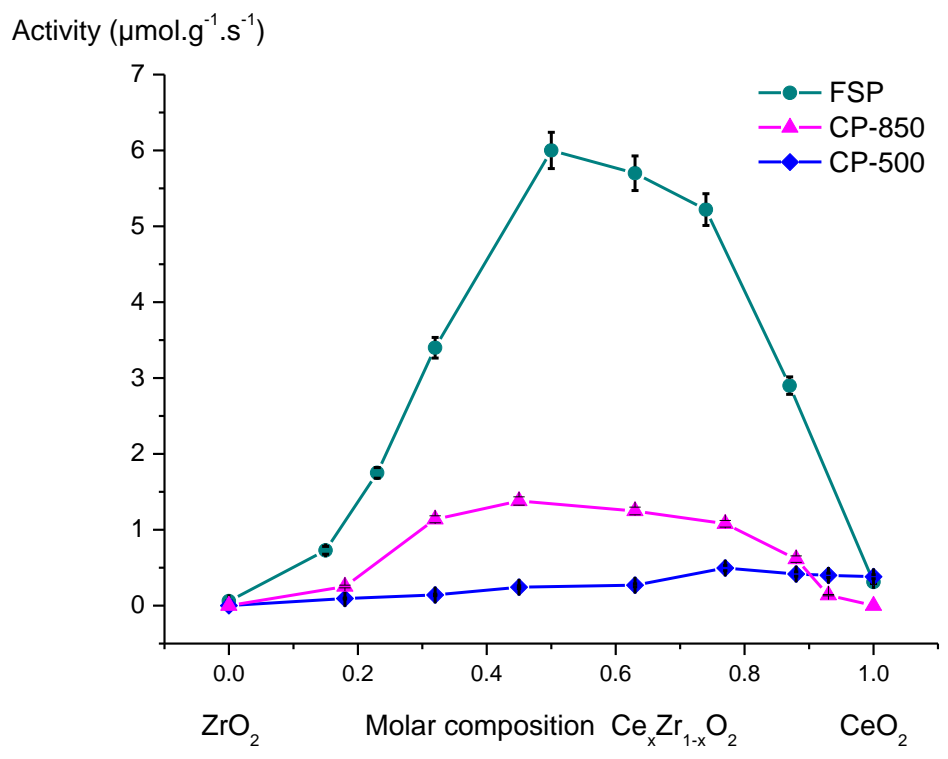

Fig. 7: Catalytic activity per unit of mass vs. molar composition $x$ for FSP $(\bullet), C P-500(\triangle)$ and $\mathrm{CP}$ $850(\Delta)$ solids. Conditions: $140^{\circ} \mathrm{C}, 4 \mathrm{~h}, 120 \mathrm{bar}, 12 \mathrm{~g}$ methanol. 


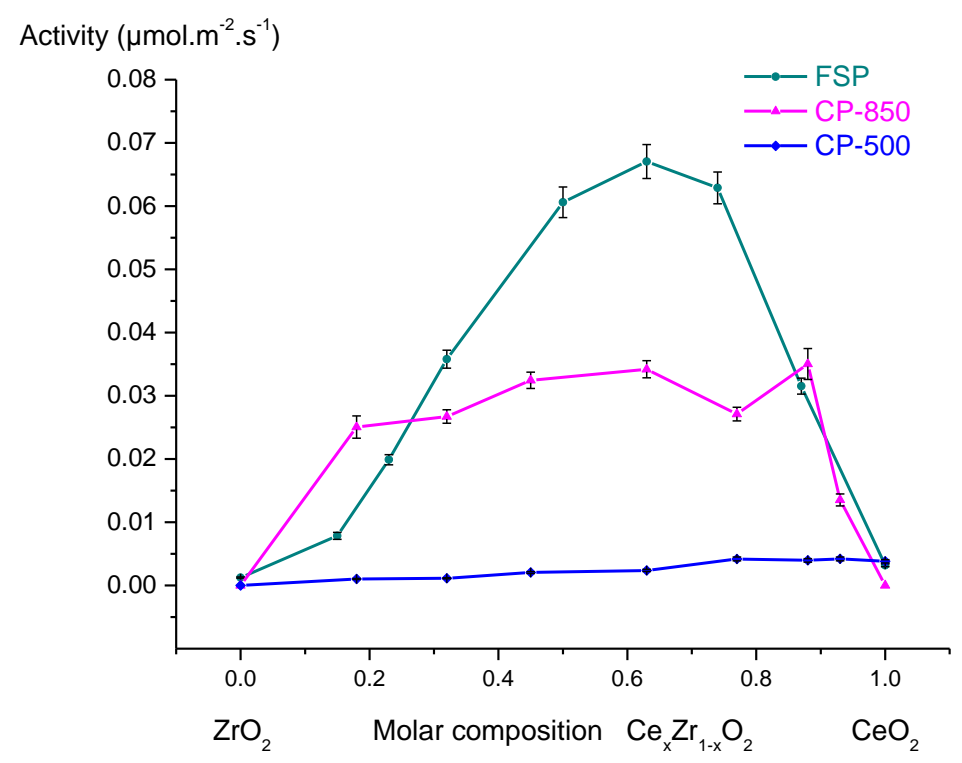

Fig. 8: Catalytic activity per unit of surface vs. molar composition $x$ for FSP $(\bullet), \mathrm{CP}-500(\triangle)$ and CP$850(\Delta)$ solids. Conditions: $140^{\circ} \mathrm{C}, 4 \mathrm{~h}, 120 \mathrm{bar}, 12 \mathrm{~g}$ methanol.

\section{Discussion}

Mixed cerium-zirconium oxides at intermediate compositions $(0.2<x<0.8)$ are more active than the pure oxides, irrespective of the synthesis method, in line with other reports using sol-gel [21] [23], coprecipitation [34] and templating [30] methods. That said, the FSP synthesis makes it possible to achieve record activity when compared to results found in the literature, i.e., about 10 times higher than most of active catalysts listed in this review [28]. To the best of our knowledge, the highest activity $\left(3 \mu \mathrm{mol} . \mathrm{g}^{-1} \cdot \mathrm{s}^{-1}\right)$ of ceria was reported by optimization of calcination temperature at $873 \mathrm{~K}$ [66] which further confirms the beneficial effect of elevated firing temperature despite lower surface area. 

for CP-850, which is the most active oxide prepared by coprecipitation. We want to stress that the synthesis of mixed oxides by precipitation, and especially the thermal treatments, have been adjusted to achieve solids whose high surface area and crystallinity are "comparable" to those of the FSP samples. For this purpose, different firing temperatures were investigated (500 and $850^{\circ} \mathrm{C}$ ). It was nonetheless impossible to achieve both high crystallinity and high surface area for the coprecipitated oxides due to the sintering of the nano-oxides. Here, we have presented characterization results obtained for coprecipitated catalysts fired at $500^{\circ} \mathrm{C}$ and $850^{\circ} \mathrm{C}$, a situation presenting the best compromise between these two criteria with the objective of establishing structure-activity relationships with FSP catalysts.

Bulk characterization techniques (X-ray diffraction and Raman spectroscopy) do not reveal any

401

402

403 differences that could be at the origin of the large difference in activities between the FSP and CP catalysts. At equimolar composition $\left(\mathrm{Ce}_{0.5} \mathrm{Zr}_{0.5}\right)$, the same tetragonal phase has been identified irrespective of the synthesis process. Also, the slight differences in surface area between the CP-500 and FSP solids (120 $\mathrm{m}^{2} \cdot \mathrm{g}^{-1}$ and $99 \mathrm{~m}^{2} \cdot \mathrm{g}^{-1}$, respectively), and hence a possibly higher number of catalytic sites, cannot account for such a large activity difference between the two catalysts. We did not observe any obvious correlations of catalytic activities with the concentration of acid or basic sites similar to those found in the literature for nanorods, nanocubes and octahedrons of ceriumzirconium oxides [67] [68][69] and for polyoxometallates [70]. In this study, the concentration of acid and basic sites for CZ-FSP and CZ-CP-850 are very similar, although the catalytic activity of the former is five-fold higher. We could hypothesize that the characterization of the acidity and basicity by the TPD of $\mathrm{NH}_{3}$ and $\mathrm{CO}_{2}$ may discriminate oxides that are poorly active or inactive from those that are active. In this study, the challenge was to determine the origin of the greatly enhanced activity of FSP mixed oxides as compared to coprecipitated mixed oxides which are already active.

As described above, neither bulk characterization nor morphological aspects can explain the superior activity of the FSP catalysts. Instead, all other analysis points toward surface aspects as an explanation. First, we have shown by XPS that the surface is enriched in cerium as compared to the bulk. This surface enrichment is very specific to flame spray pyrolysis, as it is not found for 
coprecipitated catalysts. We can propose that the cerium enrichment at the surface may originate

419

420

421

422

423 from the very high temperature which permits the surface composition to be at equilibrium. This hypothesis is supported by theoretical study which shows by a combination of density functional theory calculations and statistical mechanics that a wide range of intermediate compositions of ceria-zirconia solid solutions are thermodynamically metastable with respect to phase separation into Ce-rich and Zr-rich phases [64]. Kinetic barriers for cation diffusion normally prevent the decomposition/segregation of ceria-zirconia solid solutions in typical "calcination" treatment or catalytic applications where low to moderate temperature are applied. But for thermal treatment at high temperature applied in ceramic materials or for catalytic converters where temperature well above $900^{\circ} \mathrm{C}$, a rearrangement of the cations in the solid solution can occur leading to phase separation. More importantly, the same study estimates that the cation rearrangement in the top (111) layer of an initial $50: 50$ solid solution leads to equilibrium Ce content of the surface of $90 \%$ while the second layer contains $70 \%$ of Zr. This theoretical study supports that (i) the top layer of CZ$\mathrm{CP}$ catalysts is composed of a $\mathrm{Ce}$ and $\mathrm{Zr}$ in equivalent concentrations as indicated by XPS measurements and (ii) the composition of top layer of CZ-FSP is very Ce-rich. The high degree of surface organization of the FSP particles observed by TEM may indicate that the surface has even reached thermodynamic equilibrium with respect to composition.

Beyond the tentative explanation of the origin of the higher catalytic activities of FSP catalysts, the assumption of surface induced Ce enrichment triggered by high temperature treatment also explains the higher activities of $\mathrm{CP}$ catalysts which are heat-treated at $850^{\circ} \mathrm{C}$. We can propose that he heat treatment at $850^{\circ} \mathrm{C}$ was high enough to trigger some Ce segregation at the surface while its concentration shall remain below those obtained by FSP.

We cannot rule out that face exposures could also account for a difference in catalytic activities. While the face exposure of FSP oxide is largely $\{111\}$, which is most classical exposed surface of Cerium Zirconium mixed oxides, the surface of $\mathrm{CP}$ oxides does not show preferential orientations. Therefore, it appears the surface exposure is not the main parameter, which governs the activity although it could contribute. 
Our hypothesis of cerium enrichment at the surface triggered by the high temperature of the FPS

446

447

448

449

450

451

452

453

454

455

456

457

458

459

460

461

462

463

464

465

466

467

468

469

470

471

472 process and its linked to enhanced catalytic performances are also supported by other experimental data.

The CZ-FSP oxide does not present the $\mathrm{Zr}-\mathrm{OH}(\mathrm{I})$ hydroxyl band at $3730-3750 \mathrm{~cm}^{-1}$, which could support the argument that the first surface layer consists mainly of cerium. Here, we want to stress that the analysis is not quantitative, as the extension coefficients are likely not the same for the different surface hydroxyls. Indeed, the presence of zirconium cations at the surface is confirmed by the methoxy band at $1153 \mathrm{~cm}^{-1}$ upon methanol adsorption. Finally, for the $\mathrm{CH}_{3} \mathrm{O}-\mathrm{Ce}(\mathrm{I})$ band at 1111 $\mathrm{cm}^{-1}$, we can clearly observe a much more intense signal for FSP than for the CP mixed oxide, which further confirms a higher concentration of cerium at the first layer of the surface. This feature is particularly relevant given that the dissociative adsorption of methanol is the first step in the catalytic mechanism, and the concentration of surface methoxide is a decisive kinetic input [39] [65] [67][68]. Daturi et al. used FTIR to quantify the adsorption of methanol on a ceria-zirconia series prepared by coprecipitation [69]. The density of methoxide (I) showed a maximum for intermediate molar composition at $\mathrm{x}=0.5$. They concluded that $\mathrm{Ce}_{0.5} \mathrm{Zr}_{0.5} \mathrm{O}_{2}$ mixed oxides prepared by coprecipitation present at their surface an optimum number of $\mathrm{Zr}^{4+}$ and $\mathrm{Ce}^{4+}$ cations of similar Lewis acid strength.

In order to further support our hypothesis on the key role of a high concentration of Ce methoxide, we quantified the density of methoxide adsorbed at the surface by measuring adsorption isotherms of methanol at $20^{\circ} \mathrm{C}$ (Fig. 9). The methanol pressure was limited to $0.1 \mathrm{kPa}$, assuming a monolayer covering of the surface below this pressure. The amount of methanol adsorbed on CZ-FSP was 8 $\mu \mathrm{mol} . \mathrm{m}^{-2}$ at $0.1 \mathrm{kPa}$, but reached only $6 \mu \mathrm{mol} . \mathrm{m}^{-2}$ and $4.2 \mu \mathrm{mol} . \mathrm{m}^{-2}$ for CZ-CP-850 and CZ-CP-500, respectively. These values are consistent with the densities of $6 \mu \mathrm{mol} . \mathrm{m}^{-2}$ and $11 \mathrm{~mol} . \mathrm{m}^{-2}$ for oxidized ceria $\{111\}$ and reduced ceria $\{111\}$, respectively [70]. Taking the surface occupied by an adsorbed methanol molecule to be $0.22 \mathrm{~nm}^{-2}$ [71], we estimated a surface of $105 \mathrm{~m}^{2} \cdot \mathrm{g}^{-1}$ for CZ-FSP using the methanol isotherm, a value close to the one determined by the BET method $\left(99 \mathrm{~m}^{2} \cdot \mathrm{g}^{-1}\right)$.

Catalytic activity is plotted as a function of the density of adsorbed methoxide for CZ-FSP, CZ-CP-500 and CZ-CP-850 in Fig. 9 . We can clearly see that the activity increases with the methoxide density, 
473 which could be a clue to the origin of the superior activity of the FSP catalysts. We acknowledge that 474 the use of adsorption isotherms does not make it possible to differentiate between monodentate 475 methoxide species and bidentate methoxide species that have been identified as active and 476 spectator species, respectively. The higher activity of the FSP catalyst and also of CZ-CP-850 to a 477 lower extend can explained by a higher density of $\mathrm{Ce}^{4+}$ surface cations that are able to activate large 478 amounts of methanol as monodentate species that are active in DMC synthesis.

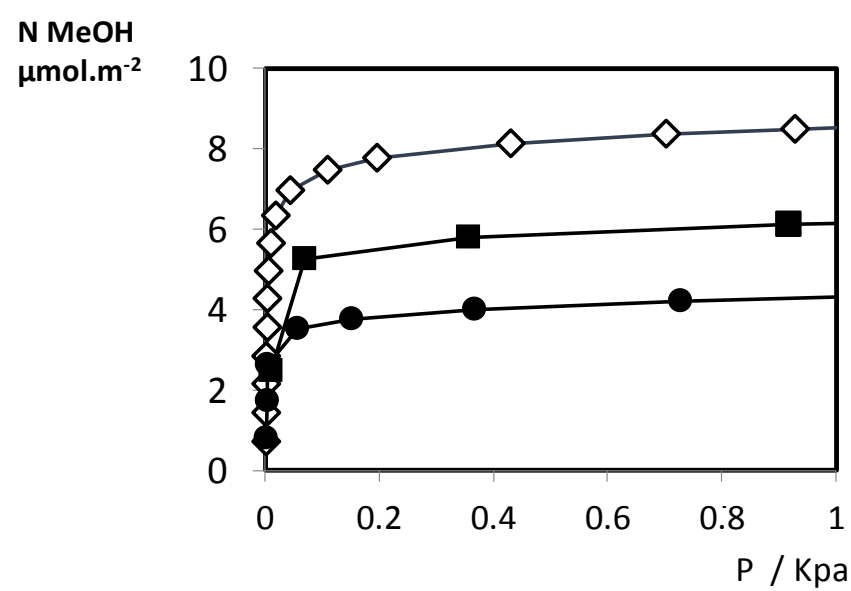

(A)

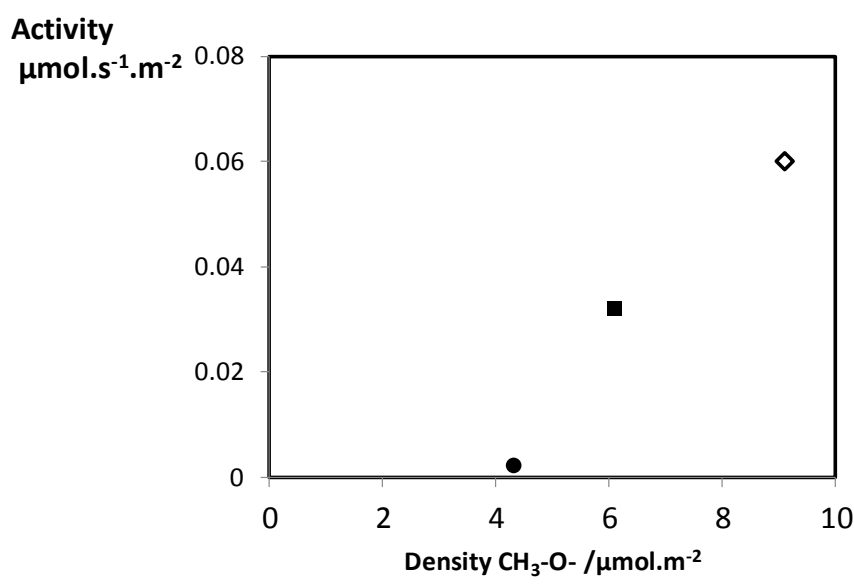

(B)

Fig. 9 (A) Isotherms of methanol at $20^{\circ}$; (B) Activity versus adsorbed methoxide surface density - CZ-CP-500 (•), CZ-CP-850 ( $\mathbf{-})$ and CZ-FSP $(\triangle)$

\section{Conclusions}

We discovered that cerium-zirconium mixed oxides prepared by flame spray pyrolysis show greater catalytic activities in DMC synthesis than those prepared by precipitation. The objective of this study was to find out the origins of the superior catalytic activities obtained by flame spray pyrolysis 
measurements using probe molecules, we propose that flame spray pyrolysis enables a surface enrichment in cerium oxide of the top layer that leads to a high concentration of adsorbed methanol at the surface, which might explain the greater activity of the catalysts prepared using this method. As pure cerium oxide is a poor catalyst, the composition of the sole top surface cannot be the only parameter, which drives the high catalytic activity. In agreement with surface composition at thermodynamic equilibrium, we propose that the most active catalysts are made with a top layer mainly consisting of cerium oxides accompanied with a second layer consisting in majority of zirconium oxide. The assumption of cerium surface enrichment triggered by thermal treatment also holds for the explanation of the high catalytic activity of coprecipitated mixed oxides, which have been treated at relative high temperature $\left(850^{\circ} \mathrm{C}\right)$

Beyond the application of DMC synthesis, we can anticipate that Flame Spray Pyrolysis synthesis shall generate relative high surface area mixed oxides with different catalytic performances with respect to mixed oxides prepared at lower temperature owing their metastable surface.

\section{Acknowledgements}

The work leading to these results received funding from the European Union Seventh Framework Program FP7-NMP-2010-Large-4, under grant agreement no. 263007 (acronym CARENA). We thank Johnson-Matthey for providing samples.

\section{REFERENCES}

[1] Y. Ono, Appl. Catal. A Gen. 155 (1997) 133-166.

[2] E.A. Quadrelli, G. Centi, J.-L. Duplan, S. Perathoner, ChemSusChem 4 (2011) 1194-1215.

[3] P. Tundo, L. Rossi, A. Loris, J. Org. Chem. 70 (2005) 2219-24.

[4] S. Memoli, M. Selva, P. Tundo, Chemosphere 43 (2001) 115-21.

[5] D. Delledonne, F. Rivetti, U. Romano, Appl. Catal. A Gen. 221 (2001) 241-251.

[6] T. Sakakura, K. Kohno, Chem. Commun. (Camb). (2009) 1312-1330.

[7] N. Keller, G. Rebmann, V. Keller, J. Mol. Catal. A Chem. 317 (2010) 1-18.

8] B. a. V. Santos, V.M. Silva, J. Loureiro, A. Rodrigues, ChemBioEng Rev. 1 (2014) 214-229. 
518 [9] M. Honda, M. Tamura, Y. Nakagawa, K. Tomishige, Catal. Sci. Technol. 4 (2014) 2830-2845.

519

520

521

522

523

524

525

526

527

528

529

530

531

532

533

534

535

536

537

538

539

540

541

542

543

544

[10] M. Honda, M. Tamura, Y. Nakagawa, S. Sonehara, K. Suzuki, K.-I.I. Fujimoto, K. Tomishige, ChemSusChem 6 (2013) 1341-4.

[11] C. Li, S. Zhong, Catal. Today 82 (2003) 83-90.

[12] A. Dibenedetto, M. Aresta, A. Angelini, J. Ethiraj, B.M. Aresta, Chemistry 18 (2012) 10324-34.

[13] A. Bansode, A. Urakawa, ACS Catal. 4 (2014) 3877-3880.

[14] A.H. Tamboli, A.A. Chaugule, H. Kim, Chem. Eng. J. 323 (2017) 530-544.

[15] S. Huang, B. Yan, S. Wang, X. Ma, Chem. Soc. Rev. 44 (2015) 3079-3116.

[16] K. Tomishige, Y. Furusawa, Y. Ikeda, M. Asadullah, K. Fujimoto, Catal. Letters 76 (2001) 71-74.

[17] K. Tomishige, T. Sakaihori, Y. Ikeda, K. Fujimoto, Catal. Letters 58 (1999) 225-229.

[18] K. Tomishige, Y. Ikeda, T. Saikahori, K. Fujimoto, J. Catal. 192 (2000) 355-362.

[19] Y. Yoshida, Y. Arai, S. Kado, K. Kunimori, K. Tomishige, Catal. Today 115 (2006) 95-101.

[20] P. Kumar, P. With, V.C. Srivastava, K. Shukla, R. Gläser, I.M. Mishra, H. Turunen, RSC Adv. 6 (2016) 110235-110246.

[21] H.J. Lee, W. Joe, J.C. Jung, I.K. Song, Korean J. Chem. Eng. 29 (2012) 1019-1024.

[22] H. Liu, W. Zou, X. Xu, X. Zhang, Y. Yang, H. Yue, Y. Yu, G. Tian, S. Feng, J. CO2 Util. 17 (2017) 43-49.

[23] H.J. Hofmann, A. Brandner, P. Claus, Chem. Eng. Technol. 35 (2012) 2140-2146.

[24] Y. Ikeda, M. Asadullah, K. Fujimoto, K. Tomishige, J. Phys. Chem. B (2001) 10653-10658.

[25] I. Prymak, O. Prymak, J. Wang, V.N. Kalevaru, A. Martin, U. Bentrup, S. Wohlrab, ChemCatChem 10 (2018) 391-394.

[26] M. Aresta, A. Dibenedetto, C. Pastore, C. Cuocci, B. Aresta, S. Cometa, E. De Giglio, Catal. Today 137 (2008) 125-131.

[27] M. Aresta, A. Dibenedetto, C. Pastore, A. Angelini, B. Aresta, I. Pápai, J. Catal. 269 (2010) 4452.

[28] K. Tomishige, Y. Gu, T. Chang, M. Tamura, Y. Nakagawa, Mater. Today Sustain. 9 (2020) 100035. 
[29] W. Sun, L. Zheng, Y. Wang, D. Li, Z. Liu, L. Wu, T. Fang, J. Wu, Ind. Eng. Chem. Res. 59 (2020) 4281-4290.

[30] P. Kumar, P. With, V.C. Srivastava, K. Shukla, R. Gläser, I.M. Mishra, RSC Adv. 6 (2016) 110235110246.

[31] Z. Fu, Y. Yu, Z. Li, D. Han, S. Wang, M. Xiao, Y. Meng, Catalysts 8 (2018).

[32] G.G. Giram, V. V. Bokade, S. Darbha, New J. Chem. 42 (2018) 17546-17552.

[33] K. Tomishige, H. Yasuda, Y. Yoshida, M. Nurunnabi, B. Li, K. Kunimori, Green Chem. 6 (2004) 206-214.

[34] A.H. Tamboli, A.A. Chaugule, S.W. Gosavi, H. Kim, Fuel 216 (2018) 245-254.

[35] A. Trovarelli, Catal. Sci. Ser. 2 (2005) 508.

[36] H. Vidal, J. Kašpar, M. Pijolat, G. Colon, S. Bernal, a Cordón, V. Perrichon, Appl. Catal. B Environ. 27 (2000) 49-63.

[37] Z.Q. Wang, M.J. Zhang, X.B. Hu, V.P. Dravid, Z.N. Xu, G.C. Guo, Chem. Commun. 56 (2020) 403-406.

[38] A.A. Marciniak, O.C. Alves, L.G. Appel, C.J.A. Mota, J. Catal. 371 (2019) 88-95.

[39] B. Liu, C. Li, G. Zhang, X. Yao, S.S.C. Chuang, Z. Li, ACS Catal. 8 (2018) 10446-10456.

[40] T. Akune, Y. Morita, S. Shirakawa, K. Katagiri, K. Inumaru, Langmuir 34 (2018) 23-29.

[41] P. Trovarelli, Alessandro; Fornasiero, Catal. Sci. Ser. Vol.12 (n.d.).

[42] C. Daniel, Y. Schuurman, D. Farrusseng, New J. Chem. 44 (2020) 6312.

[43] W.J. Stark, L. Mädler, M. Maciejewski, S.E. Pratsinis, A. Baiker, Chem. Commun. 38(4) (2003) 588-589.

[44] W.J. Stark, M. Maciejewski, L. Mädler, S.E. Pratsinis, A. Baiker, J. Catal. 220 (2003) 35-43.

[45] W.Y. Teoh, R. Amal, L. Mädler, Nanoscale 2 (2010) 1324-1347.

[46] D. Fernández-Torre, K. Kośmider, J. Carrasco, M.V. Ganduglia-Pirovano, R. Pérez, J. Phys. Chem. C 116 (2012) 13584-13593.

[47] L. Mädler, W.J. Stark, S.E. Pratsinis, J. Mater. Res. 17 (2002) 1356-1362.

[48] A.P. Bechepeche, O. Treu, E. Longo, C.O. Paiva-Santos, J.A. Varela, J. Mater. Sci. (1999). 
[49] F. Zhang, C.H. Chen, J.C. Hanson, R.D. Robinson, I.P. Herman, S.W. Chan, J. Am. Ceram. Soc. (2006).

[50] A.E. Nelson, K.H. Schulz, Appl. Surf. Sci. 210 (2003) 206-221.

[51] E. Djurado, P. Bouvier, G. Lucazeau, J. Solid State Chem. 149 (2000) 399-407.

[52] D.G. Lamas, G.E. Lascalea, R.E. Juárez, E. Djurado, L. Pérez, N.E. Walsöe de Reca, J. Mater. Chem. 13 (2003) 904-910.

[53] R. Si, Y.W. Zhang, S.J. Li, B.X. Lin, C.H. Yan, J. Phys. Chem. B 108 (2004) 12481-12488.

[54] J.E. Spanier, R.D. Robinson, F. Zhang, S.-W. Chan, I.P. Herman, Phys. Rev. B 64 (2001) 245407.

[55] A. Mineshige, T. Taji, Y. Muroi, M. Kobune, S. Fujii, N. Nishi, M. Inaba, Z. Ogumi, Solid State Ionics 135 (2000) 481-485.

[56] D.H. Prasad, S.Y. Park, H.-I. Ji, H.-R. Kim, J.-W. Son, B.-K. Kim, H.-W. Lee, J.-H. Lee, J. Phys. Chem. C 116 (2012) 3467-3476.

[57] G.W. Graham, C.L. Roe, L.P. Haack, A.M. Straccia, J. Vac. Sci. Technol. A Vacuum, Surfaces, Film. 18 (2000) 1093.

[58] a. Galtayries, R. Sporken, J. Riga, G. Blanchard, R. Caudano, J. Electron Spectros. Relat. Phenomena 88-91 (1998) 951-956.

[59] Y. Pu, K. Xuan, F. Wang, A. Li, N. Zhao, F. Xiao, RSC Adv. 8 (2018) 27216-27226.

[60] T. Merle-Méjean, P. Barberis, S.B. Othmane, F. Nardou, P.E. Quintard, J. Eur. Ceram. Soc. 18 (1998) 1579-1586.

[61] C. Binet, M. Daturi, J.-C. Lavalley, Catal. Today 50 (1999) 207-225.

[62] E. Finocchio, M. Daturi, C. Binet, J.C. Lavalley, G. Blanchard, Catal. Today 52 (1999) 53-63.

[63] M. Daturi, C. Binet, J.C. Lavalley, G. Blanchard, Surf. Interface Anal. 30 (2000) 273-277.

[64] M. Daturi, E. Finocchio, C. Binet, J.C. Lavalley, F. Fally, V. Perrichon, J. Phys. Chem. B 103 (1999) 4884-4891.

[65] M. Daturi, C. Binet, J. Lavalley, R. Sporken, Phys. Chem. Chem Phys. 1 (1999) 5717-5724.

[66] M. Honda, M. Tamura, Y. Nakagawa, K. Nakao, K. Suzuki, K. Tomishige, J. Catal. 318 (2014) 95107. 
599 [67] S. Wang, L. Zhao, W. Wang, Y. Zhao, G. Zhang, X. Ma, J. Gong, Nanoscale 5 (2013) 5582-8.

600 [68] M. Capdevila-Cortada, G. Vilé, D. Teschner, J. Pérez-Ramírez, N. López, Appl. Catal. B Environ. $601 \quad 197(2016)$ 299-312.

602 [69] Y. Fu, T. Hong, J. Chen, Thermochim. Acta 434 (2005) 22-26.

603 [70] H.J. Lee, S. Park, J.C. Jung, I.K. Song, Korean J. Chem. Eng. 28 (2011) 1518-1522.

604 [71] S.S. Xie, A.A.T. Bell, Catal. Letters 70 (2000) 137-143.

605 [72] P. Unnikrishnan, S. Darbha, J. Chem. Sci. 128 (2016) 957-965.

606 [73] D.R. Mullins, P.M. Albrecht, F. Calaza, Top. Catal. 56 (2013) 1345-1362.

607 [74] A. Badri, J.C. Lavalley, C. Binet, J. Chem. Soc. Faraday Trans 93 (1997) 1168.

608

609 